\title{
Thermosonication and optimization of stingless bee honey processing
}

\begin{abstract}
The effects of thermosonication on the quality of a stingless bee honey, the Kelulut, were studied using processing temperature from 45 to $90{ }^{\circ} \mathrm{C}$ and processing time from 30 to 120 minutes. Physicochemical properties including water activity, moisture content, color intensity, viscosity, hydroxymethylfurfural content, total phenolic content, and radical scavenging activity were determined. Thermosonication reduced the water activity and moisture content by $7.9 \%$ and $16.6 \%$, respectively, compared to $3.5 \%$ and $6.9 \%$ for conventional heating. For thermosonicated honey, color intensity increased by $68.2 \%$, viscosity increased by $275.0 \%$, total phenolic content increased by $58.1 \%$, and radical scavenging activity increased by $63.0 \%$ when compared to its raw form. The increase of hydroxymethylfurfural to $62.46 \mathrm{mg} / \mathrm{kg}$ was still within the limits of international standards. Optimized thermosonication conditions using response surface methodology were predicted at $90^{\circ} \mathrm{C}$ for 111 minutes. Thermosonication was revealed as an effective alternative technique for honey processing.
\end{abstract}

Keyword: Honey quality; Physicochemical properties; Stingless bee honey; Thermal processing; Thermosonication 